\title{
Pinijev sprevodni prelec (Thaumetopoea pityocampa) v Sloveniji
}

\section{Maja JURC $^{1 *}$, Tine HAUPTMAN ${ }^{1}$, Roman PAVLIN ${ }^{1}$, Daniel BORKOVIČ ${ }^{1}$, Zoran ZAVR- TANIK ${ }^{2}$, Vida PAPLER-LAMPE ${ }^{3}$}

Dne 26.3.2019 smo sodelavci Katedre za zdravje gozda in upravljanje prostoživečih živali Oddelka za gozdarstvo in obnovljive gozdne vire, Biotehniške fakultete (prof. dr. M. Jurc, R. Pavlin, doc. dr. T. Hauptman, D. Borkovič) skupaj s kolegi z Inštituta za gozdno entomologijo, gozdno patologijo in varstvo gozdov (Institut für Forstentomologie, Forstpathologie und Fortschutz IFFF), ki je del dunajske Univerze za kulturo tal (Universität für Bodenkultur Wien - BOKU) (prof. dr. C. Stauffer, prof. dr. A. Schopf in M. Schebeck) ter Zavoda za gozdove Slovenije (Z. Zavrtanik) obiskali lokacijo Log pod Mangartom in ugotavljali razširjenost pinijevega sprevodnega prelca (slika 1).
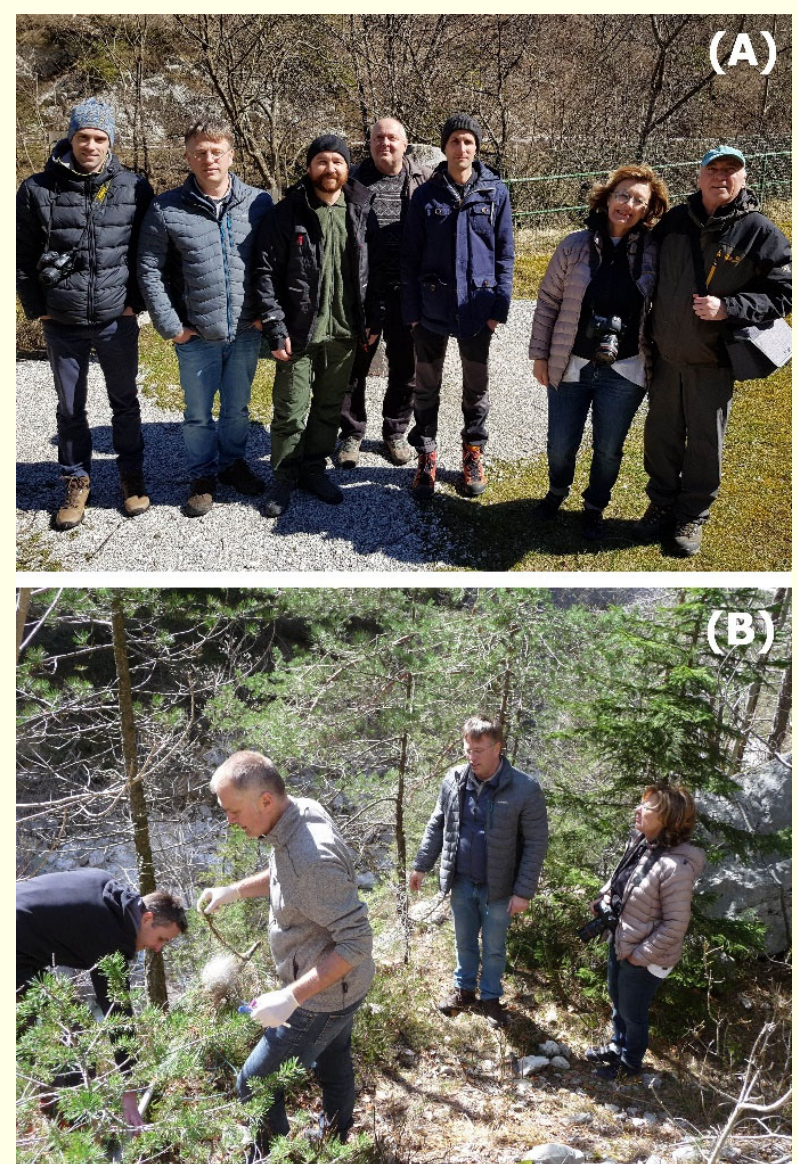

Slika 1a,b: Udeleženci ekskurzije na lokaciji Log pod Mangartom, 26.2.2019 (foto: C. Stauffer, A. Schopf)

Razširjenost te vrste smo v Sloveniji ugotavljali leta 2014 (Roques in sod., 2015). Kolegi iz Avstrije so letos vzorčili ličinke tudi v Italiji (lokacija Naborjet / Malborghetto) ter v Avstriji (lokacija Dobrač / Dobratsch) z namenom ugotavljanja izvora avstrijske populacije pini- jevega sprevodnega prelca. Na naši lokaciji smo ugotovili šibko gostoto populacije metulja, saj so bila posamična gnezda gosenic prisotna na manjšem številu pregledanih gostiteljskih dreves (Pinus nigra, P. sylvestris) (slika 2). Zanimiva je bila informacija avstrijskih kolegov o letošnjem pojavu gradacije metulja v okolici Beljaka (Villach, Avstrija).

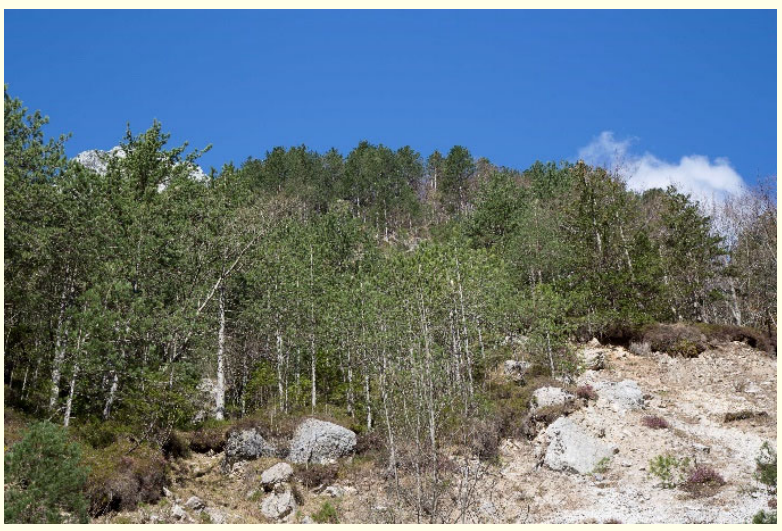

Slika 2: Leta 2011 je bil T. pityocampa zabeležen na lokaciji Log pod Mangartom. Obisk lokacije Log pod Mangartom (dolina Možnice) 26.2.2019 je pokazal le sporadičen napad pinijevega sprevodnega prelca (foto: M. Jurc)

Iz zgodovine pinijevega sprevodnega prelca

Prvi zapis o pinijevem sprevodnem prelcu (Thaumetopoea pityocampa (Denis in Schiffermüller, 1775); Thaumetopoeidae, Lepidoptera) v Sloveniji sega v leto 1904 (lokacija: Komen in okolica). Razširil se je iz Furlanije v Italiji, kjer je bil zabeležen že leta 1898 (Kafol, 1951). $\mathrm{S}$ pogozdovanjem kraških goličav, predvsem s črnim borom, so nastale ustrezne trofične razmere za gosenice pinijevega sprevodnega prelca. Leta 1906 je bil že tako razširjen, da so ga začeli zatirati. Danes je T. pityocampa prisoten v zahodnem delu Slovenije, v regijah Istre, Krasa, Primorske in Tolmina (Jurc in sod., 2003). V zadnjih petnajstih letih so bila gnezda/zapredki pinijevega sprevodnega prelca opažena $v$ zgornji Primorski regiji okrog Bovca in nad Logom pod Mangartom na 1.200 m.n.v. To so najsevernejše ugotovljene lokacije te vrste pri nas.

V letih 2010 in 2011 se je vrsta razširila na širše območje v južnem delu Slovenije pri Ilirski Bistrici. Leta 2011 je bil T. pityocampa zabeležen pri Bohinjski Bistrici (Notranji Bohinj), v osrčju Julijskih Alp ter na lokaciji Log pod Mangartom (Roques, Jurc, Podlesnik in sod. 2015).

V letu 2019 smo načrtovali ponovno evidentiranje razširjenosti $T$. pityocampa na severnejših lokacijah v 
Sloveniji s kolegi iz Avstrije ter Zavoda za gozdove Slovenije (Zoran Zavrtanik, GGO Tolmin, Vida PaplerLampe, GGO Bled). Na lokaciji pri Bohinjski Bistrici so bili v žledolomu 2014 uničeni vsi bori, napadeni leta 2011 (ZGS, 2015).

\section{Dinamika populacije $T$. pityocampa in obdobja namnožitev}

Namnožitve $T$. pityocampa so se večinoma pojavljale $\mathrm{v}$ letih z višjimi povprečnimi temperaturami in so trajale le kratek čas. Gradacije so bile zabeležene v letih 19281929, 1937-1938, 1944-1945, 1948-1950, 1953-1954, 1958-1959, 1965-1966, 1969-1970, 1972-1973, 1976$1979,1982-1983$ in $1992-1993$, večinoma na Krasu okoli Črnega Kala, Ospa, Socerba, Sočerge, Kubeda, Dekanov in Škofij. Posebej izrazite gradacije so bile zabeležene med letoma 1944 in 1950, tako je leta 1949 na 259 ha sestojev $P$. nigra stopnja osutosti iglic znašala 25-100\%. Leta 1950 so v kraški regiji zatirali ličinke z odstranjevanjem zapredkov ter uporabo insekticidov več kot 1.502 ha nasadov črnega bora so $\mathrm{z}$ letalom tretirali s Pantakanom E-16,5 (koncentrat za emulzijo, 16,5\% DDT) (Kafol, 1951; Titovšek, 1994; Jurc in sod., 2003). Zanimiva je bila izkušnja Avgusta Kafola iz Komna, ki je leta $1950 »$ »koli gozdne drevesnice v Komnu okoli 17. ure oprašil s pantakanom (5\%) zapredke na dveh borovcih, deloma pa tudi na zemlji. Veselje je bilo gledati, kako jih siničke odnašajo in pokončujejo«. V zadnjem času so se namnožitve pojavile v GGO Tolmin in na Kraškem GGO, in sicer v letih 2015 (ZGS, 2015) in 2016 (Zavrtanik in Košiček, 2016).

\section{Bioekologija pinijevega sprevodnega prelca}

$T$. pityocampa se pri nas pojavlja na robu svojega areala - vrsta je prisotna v območjih, kjer so junijske izoterme okoli $22^{\circ} \mathrm{C}$. Razvije eno generacijo na leto, roji od julija do avgusta (slika 3, 4); v teh mesecih zalega do 200 zelenkastih jajčec v rokavčku okrog borovih iglic, ki jih prekrije s srebrnimi luskicami s kril.

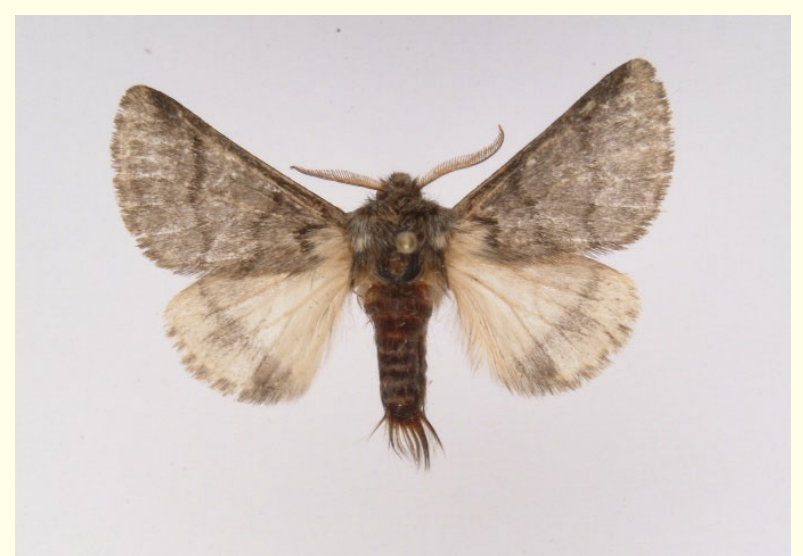

Slika 3: Pinijev sprevodni prelec T. pityocampa, samec (foto: M. Jurc)

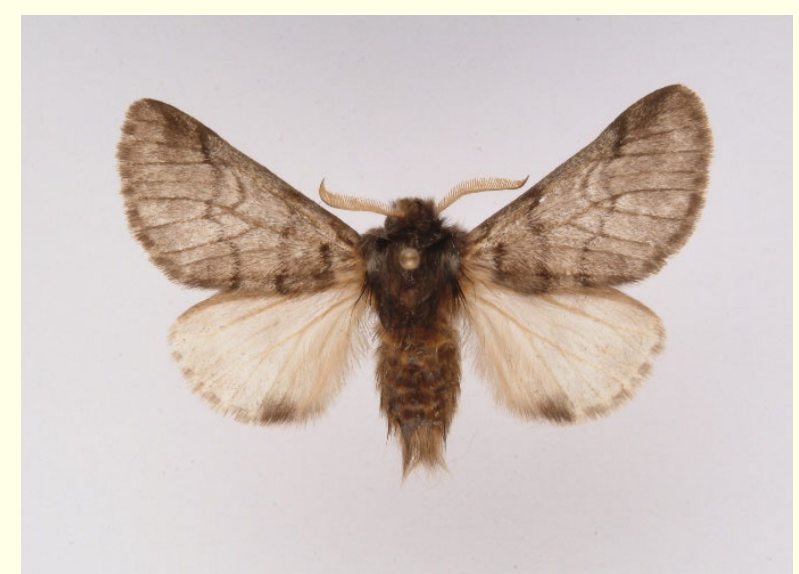

Slika 4: Pinijev sprevodni prelec T. pityocampa, samica (foto: M. Jurc)

Embrionalni razvoj se konča v 14 dneh. Gosenice se razvijajo v zapredkih/gnezdih v krošnji borov, iz katerih se ponoči selijo na mesta prehranjevanja $\mathrm{v}$ procesiji druga za drugo in obžirajo iglice (slika 5,6).

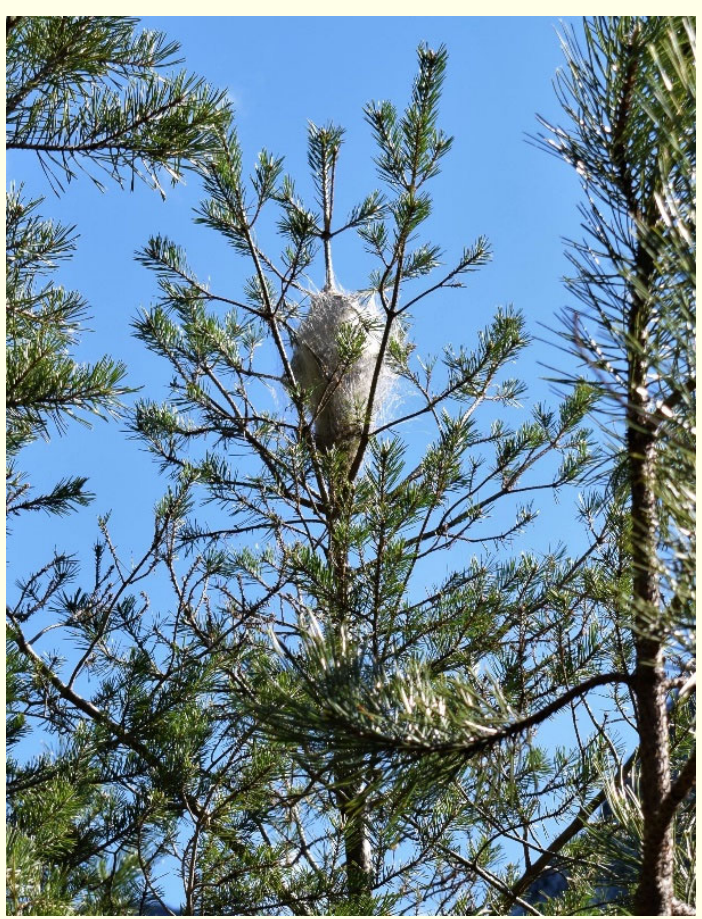

Slika 5: Zapredek pinijevega sprevodnega prelca, 26.3.2019 (foto: T. Hauptman)

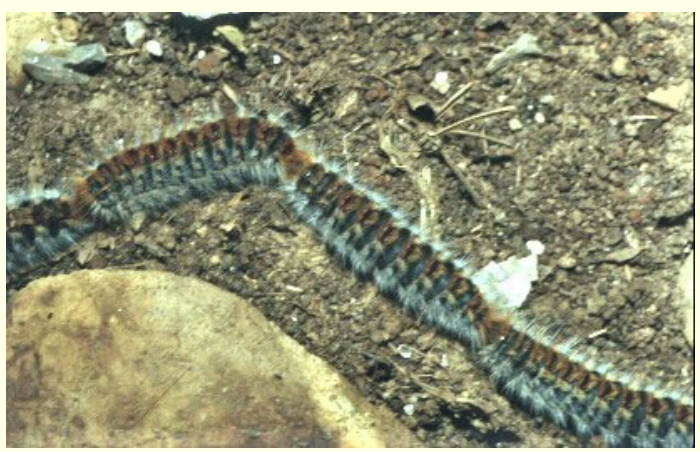

Slika 6: Gosenice pinijevega sprevodnega prelca se ponoči v procesiji selijo na mesta obžiranja borovih iglic (foto: D. Jurc, 17.4.2003, Ilirska Bistrica) 
Ko doraščajo, se gnezdo z gosenicami in njihovimi iztrebki povečuje. $\mathrm{V}$ enem gnezdu lahko prebiva od 50 do 150 gosenic. V zapredku, kjer so temperature v povprečju od 8 do $10^{\circ} \mathrm{C}$, prezimijo. Prenesejo nizke temperature $\left(\right.$ do $\left.-29^{\circ} \mathrm{C}\right)$, vlažne zime pa povzročajo veliko mortaliteto gosenic (Kafol, 1951). Ličinke prezimijo na četrtem stadiju razvoja v zapredkih. Pozno pozimi ali zgodaj spomladi se ličinke spet aktivirajo in se začnejo hraniti, dokler ne dosežejo pete razvojne stopnje. Od 15. marca do 1. maja se ličinke zakopljejo v tla, kjer se zabubijo. Na lokaciji Log pod Mangartom so bile gosenice 26.3.2019 še v zapredkih, torej se selitev v tla in zabubljenje še ni začelo (slika 7, 8).

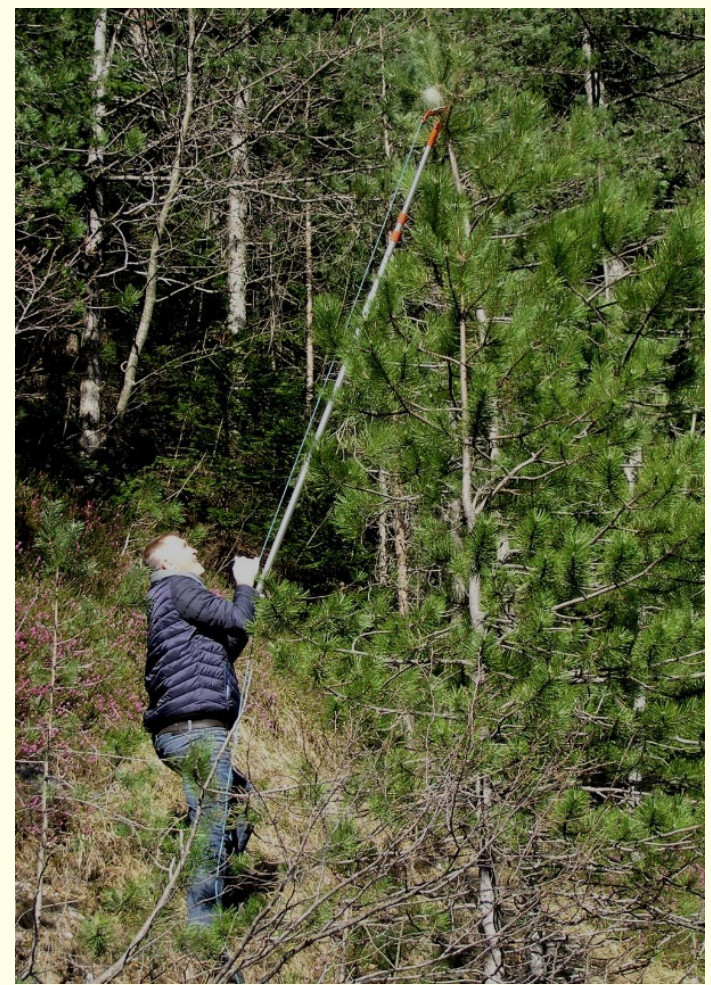

Slika 7: Prof. C. Stauffer odstranjuje zapredek T. pityocampa, 26.3.2019 na lokaciji Log pod Mangartom (foto: R. Pavlin)

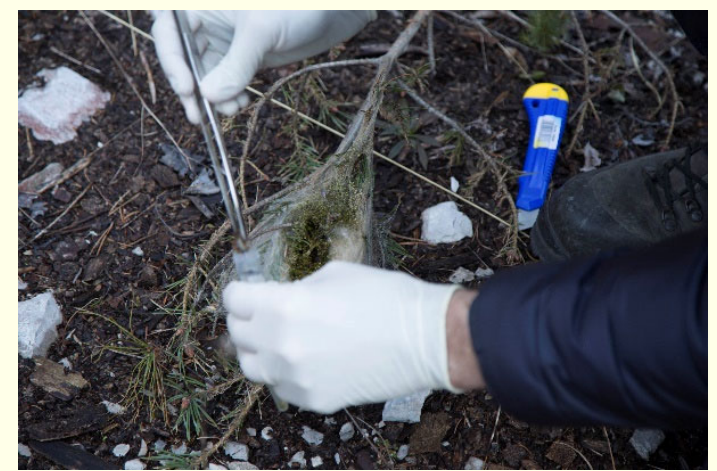

Slika 8: Zaradi nevarnih drobnih ožigalnih dlačic na telesu gosenic, ki ob dotiku s človeško kožo povzročajo vnetja (gosenični dermatitis ali »lepidopterizem«) vzorce gosenic nabiramo z ustrezno opremo (foto: M. Jurc)

Večinoma se zapredki pojavijo na obrobnih drevesih sestojev v zgornji polovici krošnje (včasih tudi nad 30 gnezd na drevo), nato se napad širi v notranjost sestoja.
V kombinaciji z drugimi škodljivimi dejavniki je nevaren škodljivi dejavnik za črni bor na Krasu. V zadnjih letih ugotavljamo, da so nasajene monokulture črnega bora odlično opravile pionirsko vlogo in izboljšale ekološke razmere do te mere, da skupaj s sestoji avtohtonih termofilnih listavcev ponekod že dosegajo povprečno slovensko gozdnatost - po podatkih ZGS znaša gozdnatost GGO Sežana 58 \%. Zaradi večje zračne vlažnosti okolja postajajo patogene glive najpomembnejši dejavnik zmanjševanja vitalnosti $P$. nigra (Jurc in Jurc, 2014).

$\mathrm{V}$ zadnjih petnajstih letih raziskovalci ugotavljajo, da $\mathrm{z}$ globalnim segrevanjem ozračja $T$. pityocampa širi svoj areal proti vzhodu Slovenije in tudi v višje nadmorske lege. Povprečne 10-letne temperature okoli leta 1970 so bile od 0,5 do $1,5^{\circ} \mathrm{C}$ nižje od povprečnih temperatur zadnjih 10 let, merjenih s šestimi vremenskimi postajami na zadevnih območjih (ARSO, 2012). To je verjetno eden od razlogov, da se je T. pityocampa razširil in se je začel pojavljati na višjih nadmorskih višinah severno od Tolminske, okoli Loga pod Mangartom. Leta 2010/2011 je bila vrsta najdena v alpski dolini pri Bohinjski Bistrici, v sestoju črnega bora, ki ga je uničil žledolom leta 2014. V zadnjih letih se je T. pityocampa razširil tudi na nove lokacije v južni Sloveniji okoli Ilirske Bistrice.

Vrsta $T$. pityocampa je, zaradi širokega areala pojavljanja v Evropi in obsežnih raziskav bioekologije in genetike, postala dobro raziskana bioindikacijska vrsta intenzivnih podnebnih sprememb, ki so tudi nedvomno znanstveno dokazane (Roques in sod., 2015).

\section{Viri}

ARSO. 2012. Arhiv Državne meteorološke službe. Ministrstvo za okolje in prostor. Agencija RS za okolje. Dostop 13.12.2012, http://www.meteo.si/

Kafol A. 1951. Iz zgodovine pinijevega sprevodnega prelca pri nas. Gozdarski vestnik, 9: 243-246.

Jurc D., Jakša J., Jurc M., Mavsar R., Matjašič D., Jonozovič M. 2003. Zdravje gozdov - Slovenija 2002. Ljubljana, Gozdarski inštitut Slovenije, Zavod za gozdove Slovenije: 69 str.

Jurc D., Jurc M. 2014. "Pa so padali bolestno, nemo, bor za borom..." - boru na Krasu so šteti dnevi. V: Roženbergar, D. (ur.), Adamič, T. (ur.). Premene malodonosnih in vrstno spremenjenih gozdov: zbornik razširjenih povzetkov. Ljubljana, Biotehniška fakulteta, Oddelek za gozdarstvo in obnovljive gozdne vire: $27-29$.

Roques A., Jurc M., Podlesnik J. in sod. 2015. Climate warming and past and present distribution of the Processionary moths (Thaumetopoea spp.) in Europe, Asia minor and North Africa. V: Roques, A. (ur.). Processionary moths and climate change: an update. Dordrecht, Heidelberg, New York, London, Springer, 427 str.

Titovšek J. 1994. Gradacije škodljivih gozdnih insektov v Sloveniji. Zbornik gozdarstva in lesarstva, 43: 31-76.

Zavrtanik Z., Košiček B. 2016. Pinijev sprevodni prelec, Thaumetopoea pityocampa (Denis \& Schiffermüller, 1775). Novice iz varstva gozdov 9: 20-21.

ZGS. 2015. Poročilo zavoda za gozdove Slovenije o gozdovih v letu 2015. Zavod za gozdove Slovenije, 131 str.

1 Univerza v Ljubljani, Biotehniška fakulteta, Oddelek za gozdarstvo in obnovljive gozdne vire Večna pot 83, 1000 Ljubljana; 2Zavod za gozdove Slovenije, Območna enota Tolmin, Tumov drevored 17, 5220 Tolmin; ${ }^{3 Z a v o d ~ z a ~ g o z-~}$ dove Slovenije, Območna enota Bled, Ljubljanska cesta 19, 4260 Bled *maja.jurc@bf.uni-lj.si 